\title{
The development of high resolution maps of tsetse abundance to guide interventions against human African trypanosomiasis in northern Uganda
}

\author{
Michelle C. Stanton ${ }^{1 *} \mathbb{D}$, Johan Esterhuizen², Inaki Tirados ${ }^{2}$, Hannah Betts ${ }^{3}$ and Steve J. Torr ${ }^{2}$
}

\begin{abstract}
Background: Vector control is emerging as an important component of global efforts to control Gambian sleeping sickness (human African trypanosomiasis, HAT). The deployment of insecticide-treated targets ("Tiny Targets") to attract and kill riverine tsetse, the vectors of Trypanosoma brucei gambiense, has been shown to be particularly cost-effective. As this method of vector control continues to be implemented across larger areas, knowledge of the abundance of tsetse to guide the deployment of "Tiny Targets" will be of increasing value. In this paper, we use a geostatistical modelling framework to produce maps of estimated tsetse abundance under two scenarios: (i) when accurate data on the local river network are available; and (ii) when river information is sparse.
\end{abstract}

Methods: Tsetse abundance data were obtained from a pre-intervention survey conducted in northern Uganda in 2010. River network data obtained from either digitised maps or derived from $30 \mathrm{~m}$ resolution digital elevation model (DEM) data as a proxy for ground truth data. Other environmental variables were derived from publicly-available resolution remotely sensed data (e.g. Landsat, $30 \mathrm{~m}$ resolution). Zero-inflated negative binomial geostatistical models were fitted to the abundance data using an integrated nested Laplace approximation approach, and maps of estimated tsetse abundance were produced.

Results: Restricting the analysis to traps located within $100 \mathrm{~m}$ of any river, positive associations were identified between the length of river and the minimum soil/vegetation moisture content of the surrounding area and daily fly catches, whereas negative associations were identified with elevation and distance to the river. The resulting models could accurately distinguish between traps with high and low fly catches (e.g. $<5$ or $>5$ flies/day), with a ROC-AUC (receiver-operating characteristic - area under the curve) greater than 0.9. Whilst the precise course of the river was not well approximated using the DEM data, the models fitted using DEM-derived river data performed similarly to those that incorporated the more accurate local river information.

Conclusions: These models can now be used to assist in the design, implementation and monitoring of tsetse control operations in northern Uganda and further can be used as a framework by which to undertake similar studies in other areas where Glossina fuscipes fuscipes spreads Gambian sleeping sickness.

Keywords: Human African trypanosomiasis, Tsetse flies, Vector control, Geostatistics, Uganda

\footnotetext{
* Correspondence: michelle.stanton@lancaster.ac.uk

${ }^{1}$ Lancaster Medical School, Lancaster University, Lancaster, UK

Full list of author information is available at the end of the article
}

(c) The Author(s). 2018 Open Access This article is distributed under the terms of the Creative Commons Attribution 4.0 International License (http://creativecommons.org/licenses/by/4.0/), which permits unrestricted use, distribution, and reproduction in any medium, provided you give appropriate credit to the original author(s) and the source, provide a link to the Creative Commons license, and indicate if changes were made. The Creative Commons Public Domain Dedication waiver (http://creativecommons.org/publicdomain/zero/1.0/) applies to the data made available in this article, unless otherwise stated. 


\section{Background}

Human African Trypanosomiasis (HAT), a severe neglected tropical disease (NTD) affecting communities in sub-Saharan Africa, is caused by two parasites, Trypanosoma brucei gambiense and T. b. rhodesiense which are transmitted to humans by the bite of tsetse flies (Glossina spp.). The two forms of the disease have distinct, non-overlapping geographical distributions, with Uganda being the only country where both forms exist $[1,2]$. The disease caused by $T . b$. gambiense, commonly referred to as Gambian sleeping sickness, is generally considered to be an anthroponosis. The disease, transmitted primarily by riverine tsetse, threatens populations in central and western parts of sub-Saharan Africa, and is responsible for $98 \%(21,862 / 22,300)$ of recent (2012-2016) HAT cases [3]. The second form of the disease, caused by $T$. $b$. rhodesiense, commonly called Rhodesian sleeping sickness, is a zoonosis which is primarily transmitted by savanna tsetse and is found in east and southern Africa. Within these geographical areas there are clusters or 'foci' of HAT transmission, with approximately 360 foci being identified with varying levels of transmission intensity across 36 countries ( 300 Gambian, 60 Rhodesian) [1]. The environmental conditions within these foci vary but tend to be remote rural areas where human populations live close to habitats suitable for tsetse.

There are two approaches to disease control recommended by the World Health Organization: the treatment of cases detected using active and passive surveillance, and vector control. Until recently, it was widely acknowledged that whilst vector control was effective for Rhodesian sleeping sickness through techniques such as treating livestock reservoir hosts with insecticides, vector control for Gambian sleeping sickness was considered infeasible at large geographical scale largely due to the costs associated with available methods of vector control [4, 5]. In response to this, cheaper methods of controlling the vectors of T. $b$. gambiense have been developed in the form of "Tiny Targets". These consist of a square panel $(25 \times 25 \mathrm{~cm})$ of blue cloth flanked by an identically-sized piece of black netting both impregnated with insecticide. The targets are deployed along the edges of rivers and lakes in areas where riverine tsetse concentrate. Studies conducted in northern Uganda have shown that the use of "Tiny Targets" is highly cost-effective in comparison to older methods of vector control $[4,6]$.

As a result of intensified efforts to control and ultimately eliminate Gambian HAT, the number of reported cases is currently on the decline, with 2131 reported globally in 2016 [3, 7]. To sustain these efforts, it is important to ensure that the new vector control strategies being adopted are suited to a range of changing environmental and epidemiological situations whilst remaining scalable and cost-effective [8]. "Tiny Targets" are deployed every 50 metres along rivers within an intervention area where either flies have been previously detected, or where the environment is deemed suitable for riverine species of tsetse, e.g. due to the presence of riparian vegetation. Targets are deployed 1-2 times per year and continuous monitoring to quantify the impact on the tsetse population is conducted using traps. Knowledge of the density and distribution of tsetse obtained by pre-intervention surveys guides the distribution of targets and location of monitoring traps and as such, systems to predict the likely fine-scale distribution and abundance of tsetse would improve ability to design and implement tsetse control operations. In the past this was done by using maps to identify rivers and aerial photographs to identify tsetse habitat. In many places however, especially in the remote areas where Gambian HAT occurs, suitable and recent maps and aerial photographs do not exist. The ability to use remotely sensed data to guide tsetse control has long been recognised [9] and has primarily been used to produce maps of tsetse presence as opposed to abundance, with earlier attempts being more focused on producing predicted output at a course spatial resolution over larger geographical areas [10-12]. In this earlier work, the resolution of the predicted output was limited by the scale of the available remotely sensed data, and as such this output was not suitable for guiding local control efforts. However, with data collected from sources such as Landsat $(30 \mathrm{~m}$ resolution, new image every 8 days), and ASTER (15-90 m resolution, new image every 16 days) becoming freely available, there is the increasing opportunity to derive maps capable of guiding local tsetse control activities [13, 14]. Further, the ability to predict abundance as opposed to presence/absence has previously been limited by the lack of suitable tsetse count data.

The aim of this study was to use a geostatistical modelling framework to explore the relationship between the natural abundance (i.e. prior to large scale tsetse control activities) of the riverine tsetse species Glossina fuscipes fuscipes, the most important vector of $T . b$. gambiense in northern Uganda and environmental variables derived from freely available remotely sensed data. A secondary aim was to determine whether river network data derived from remotely sensed digital elevation data served as a suitable proxy to locally verified river network data, as this more detailed information is frequently unavailable in HAT endemic areas.

\section{Methods}

\section{Study area}

In north-west Uganda, G. $f$. fuscipes is the vector of $T . b$. gambiense. All field data used in the present study are from Arua, Koboko, Maracha and Yumbe Districts (Fig. 1), a densely settled rural area comprising small-scale farms producing a mixture of subsistence (e.g. cassava, matoke, peanuts) and cash (tobacco) crops and low numbers of 


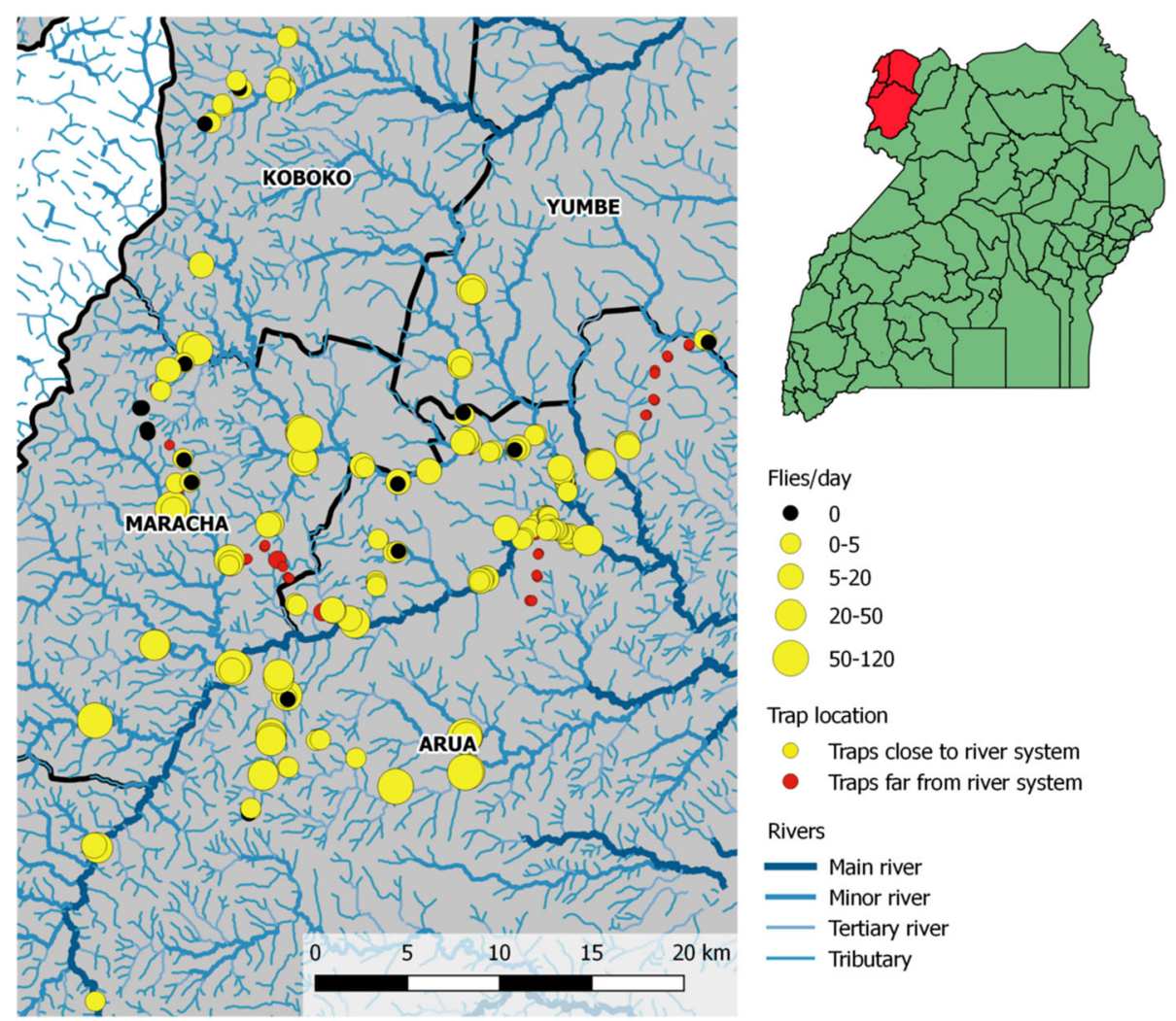

Fig. 1 Map depicting the locations of the 236 tsetse traps deployed between October-December 2010 in north west Uganda, and the resulting average daily tsetse count. The location of the surveyed Districts (Arua, Maracha, Koboko and Yumbe) is highlighted in red in the map of Uganda

livestock (cattle, pigs, goats). There are two large perennial rivers (Enyau, Kochi) which flow into the Nile and large numbers of smaller tributaries and seasonal streams. Narrow $(2-5 \mathrm{~m})$ and intermittent bands of natural vegetation (e.g. Cynometra alexandri, Entada abyssinica, Acacia seyal, Ekebergia capensis, Plectranthus barbatus and Schrebera alata) are associated with these rivers and streams. Wild mammalian hosts are rare and the main hosts of tsetse are reptiles (Monitor lizard), cattle, pigs and humans [4].

\section{Tsetse survey data}

A tsetse survey was undertaken in October to December 2010 to provide baseline information on the G. f. fuscipes distribution prior to undertaking a "Tiny Target" intervention study [4]. A total of 236 pyramidal traps [15] were deployed across an area of $985 \mathrm{~km}^{2}$, and daily tsetse counts were recorded for a period of 1-8 days (median 3 days). These data can be accessed in the Additional file 1. The majority of traps $(\sim 90 \%)$ were placed along the banks of rivers and streams as this was habitat known to be associated with G. $f$. fuscipes. As it was unclear whether flies were likely to be found in areas further from riverine areas, additional traps $(\sim 10 \%)$ were placed further from the river network in nearby farming areas (Fig. 1).

\section{Environmental data}

Landsat 5 Thematic Mapper (TM) imagery was obtained for the study area for December 2009 as low cloud cover images were unavailable for the precise time of the survey. Landsat $5 \mathrm{TM}$ is comprised of seven spectral bands, six of which have a $30 \mathrm{~m}$ spatial resolution (3 visible, near infrared (NIR), 2 shortwave infrared (SWIR)), and one with a $120 \mathrm{~m}$ spatial resolution [thermal infrared (TIR)] which was resampled to $30 \mathrm{~m}$ by the United States Geological Survey (USGS) prior to being download from the USGS Earth Explorer (http://earthexplorer.usgs.gov). From this the Enhanced Vegetation Index (EVI), Land Surface Temperature (LST) and a Soil Moisture Index (SMI) at 30 $\mathrm{m}$ spatial resolution were calculated as detailed in Table 1. A priori, EVI, LST, SMI and band 7 (SWIR with wavelength $2.08-2.35 \mu \mathrm{m}$ ) were considered to be the variables that were most likely to be associated with tsetse presence and abundance $[10,16]$. The values of the four environmental measures were obtained at each trap location, in addition to the mean, minimum, maximum and standard deviation values within a $350 \mathrm{~m}$ radius, which corresponds approximately to the estimated daily dispersal rate of male G. f. fuscipes [17].

River data were obtained from the Government of Uganda 1:50,000 maps, which were then converted into 
Table 1 Summary of environmental data considered when fitting binary logistic and negative binomial geostatistical models to tsetse catch data

\begin{tabular}{|c|c|c|c|c|c|}
\hline Environmental variable & $\begin{array}{l}\text { Trap data } \\
\text { range }\end{array}$ & Source & Spatial resolution (m) & Time period & Derivation \\
\hline $\begin{array}{l}\text { Enhanced vegetation } \\
\text { index (EVI) }\end{array}$ & $0.07-0.19$ & Landsat 5 & 30 & December 2009 & $\left\{\frac{N R R-R e d}{N / R+6 \times R E D-7.5 \times B L U E+1}\right\}$ \\
\hline Soil Moisture Index (SMI) & $0.33-0.64$ & Landsat 5 & 30 & December 2009 & $\begin{array}{l}\frac{T s m a x-T s}{T s m a x-T s m i n} \text {, where Tsmax and Tsmin are } \\
\text { the maximum and minimum surface } \\
\text { temperatures for a given Normalised } \\
\text { Difference Vegetation Index (NDVI) } \\
\text { value. See Wang et al. [38] }\end{array}$ \\
\hline $\begin{array}{l}\text { At-satellite brightness } \\
\text { temperature }\left({ }^{\circ} \mathrm{C}\right)\end{array}$ & $25.1-28.9$ & Landsat 5 & 30 & December 2009 & $\begin{array}{l}\text { Thermal Infrared Sensor (TIRS) band } \\
\text { i.e. Band } 6\end{array}$ \\
\hline $\begin{array}{l}\text { Land surface temperature } \\
\text { (LST) }\end{array}$ & $27.9-34.5$ & Landsat 5 & 30 & December 2009 & $\begin{array}{l}\text { At-satellite brightness temperature } \\
\text { and NDVI were used to derive LST. } \\
\text { Details on the algorithms used can } \\
\text { be found in Ndossi et al. [39] }\end{array}$ \\
\hline Elevation (m) & $852-1210$ & $\begin{array}{l}\text { Shuttle Radar Topography } \\
\text { Mission (SRTM) }\end{array}$ & 30 & 2000 & SRTM Void Filled data \\
\hline Slope $\left(^{\circ}\right)$ & $0-7.8$ & $\begin{array}{l}\text { Shuttle Radar Topography } \\
\text { Mission (SRTM) }\end{array}$ & 30 & 2000 & $\begin{array}{l}\text { Derived from SRTM elevation data } \\
\text { using the hydrology tools within the } \\
\text { Spatial Analyst Toolbox of ArcGIS } \\
\text { (version 10.3.1) }\end{array}$ \\
\hline Flow accumulation & $0-1451$ & $\begin{array}{l}\text { Shuttle Radar Topography } \\
\text { Mission (SRTM) }\end{array}$ & 30 & 2000 & $\begin{array}{l}\text { Derived from SRTM elevation data } \\
\text { using the hydrology tools within the } \\
\text { Spatial Analyst Toolbox of ArcGIS } \\
\text { (version 10.3.1) }\end{array}$ \\
\hline Fragmentation indices & Various & $\begin{array}{l}\text { Advanced Spacebourne } \\
\text { Thermal Emission and } \\
\text { Reflection Radiometer } \\
\text { (ASTER) }\end{array}$ & 15 & December 2010 & $\begin{array}{l}\text { Calculate Normalised Difference } \\
\text { Vegetation Index, i.e. NDVI = NRR-Red } \\
\text { and using a threshold of } 0 \text {, designate } \\
\text { pixels as either vegetated or not } \\
\text { vegetated. The R package SDMTools } \\
\text { was then used to derive the following } \\
\text { patch statistics within } 350 \mathrm{~m} \text { of the trap: } \\
\text { - Average distance between patches } \\
\text { - Maximum distance between patches } \\
\text { - Number of patches } \\
\text { - Area covered by patches } \\
\text { - Size of largest patch }\end{array}$ \\
\hline
\end{tabular}

shapefiles with each section of river being coded as either main, minor, tertiary, tributary. Further hydrological information was derived from $30 \mathrm{~m}$ resolution digital elevation model (DEM) data obtained from the Shuttle Radar Topography Mission (SRTM), accessed via the USGS Earth Explorer, i.e. flow direction and flow accumulation as proxy river data. To reflect the situation where there were no accurate river data available for the study area, the proxy river data was derived independently of the river network data that were digitised from published maps. A trial-and-error approach was used to determine a suitable flow accumulation threshold above which it was assumed a river was present. High resolution commercial imagery accessed via Google Earth and Bing was used as reference data for this approach. From this a proxy river network was derived and this network was categorised using the Strahler stream order. The raw flow accumulation values (mean, min, max, total) within $350 \mathrm{~m}$ of a trap plus the proportion of cells within $350 \mathrm{~m}$ of a trap that exceeded a range of flow accumulation thresholds were then calculated, in addition to the distance between the traps and the resulting proxy river network.

Habitat fragmentation measures were based on vegetation values derived at a $15 \mathrm{~m}$ resolution using ASTER data, accessed using the USGS Earth Explorer for December 2010. As ASTER data do not include a blue spectral band, it was not possible to derive EVI, hence NDVI (Table 1) was used to identify vegetated from non-vegetated cells, using a threshold of zero. From this, fragmentation indices for the surrounding landscape were calculated, including the average nearest patch distance, total number of vegetated cells and maximum patch size within a $350 \mathrm{~m}$ radius of each trap [18-20].

Summaries of the environmental data used in this analysis, and the range of each variable covered by the 236 trap locations are shown in Table 1. 


\section{Statistical analysis}

An initial exploratory data analysis was undertaken to determine the likely form of the association between the environmental variables under consideration and fly abundance (average number of flies per trap per day), consisting of scatterplots and simple correlation calculations. Following this, a generalised linear geostatistical model (GLGM) was developed for identifying significant relationships between the total number of tsetse caught in each trap and the environmental covariates. The number of days each trap was operated was included as an offset in the model. The geostatistical modelling framework accounts for the presence of spatial dependency in the trap count data which was not explained by the available environmental variables. Importantly, whilst the model was developed for count data, the application of the model was not to enable precise predictions of fly abundance, but rather to differentiate areas of high and low abundance. As such, an additional predicted outcome of interest was in the form of a relative abundance category as opposed to the exact abundance.

To account for a frequently encountered scenario of there being a lack of reliable local information on the location of the river networks, two forms of the model were considered: one which considered the inclusion of data derived from the Government of Uganda maps (GLGM-River), and one which considered the inclusion of the flow accumulation and proxy river network data derived from the DEM data (GLGM-Proxy). Model fitting was undertaken using an integrated nested Laplace approximation (INLA) in $\mathrm{R}$ (version 3.3.1) using the R-INLA package (www.r-inla.org) [21-23] and a stochastic partial differential equation (SPDE) approach [21, 24]. Within the R-INLA package we considered modelling the count data using Poisson and negative binomial distributions and their respective type 1 zero-inflated versions to account for the excess number of traps were no flies were caught. Details of these can be found within the R-INLA documentation [25].

A systematic approach was adopted to model fitting with the aim of determining a parsimonious model capable of predicting fly abundance. First, the Pearson's correlation between each of the continuous variables was calculated, and where the correlation exceeded 0.7, only one of the variables was selected to be considered in the model. Following this, the potential set of covariates was reduced further by fitting a regression model to the full data set and applying a Lasso (Least Absolute Shrinkage and Selection Operator) penalty. INLA was then used to fit the GLGMs to the data, which each included a single environmental variable. Where appropriate, various transformations (e.g. square root, log-transformed) of, and interactions between, the environmental variables were considered to account for non-linear relationships between the environment and the outcome. For each fitted model, the Watanabe-Akaike information criterion (WAIC) was obtained, allowing the relative fit of each model to be compared [26]. Models were then ranked according to their WAIC, with smaller values indicating better predictive values. Starting with the model with the smallest WAIC, environmental covariates were added to the model one at a time according to their rank order. Initially a zero-inflated negative binomial was used during the model selection process. The WAIC was then used to compare this to less complex negative binomial and Poisson models, plus make a comparison between models with and without a spatial term.

The performance of the models was then assessed with respect to their goodness of fit, both absolutely and within fly abundance categories. Using R-INLA, 1000 samples were drawn from the posterior distributions of the fitted models (see Additional file 2) to enable summary measures of the fitted values to be produced. Firstly, the root mean square error of the fitted model was assessed using the posterior mean as the fitted model estimate of fly catches. In addition, the fitted probability $p_{i j}$ that the fly count at trap $i$ was within the range of the observed count category $j$ was obtained. In practice, this was obtained using the proportion of the 1000 posterior samples that were within each category. Violin plots of $p_{i c}$ by observed category were then produced, where $p_{i c}$ is the fitted probability that trap $i$ was within the range of the correct observed count category $c$. Categories considered were based on terciles of the catch data ('low', 'medium,' 'high'), plus a range of binary categories were also considered. Using a threshold based on the average number of flies caught per trap per day to divide the data into two categories, the Brier score [27] and receiver-operating characteristic (ROC) curve [28] were obtained for the fitted models as a measure of how well the model was able to discriminate between the categories. The Brier score is the sum of the squared difference between the observed outcome $y_{i}$, which is equal to 1 if the binary threshold is exceeded and zero otherwise, and the fitted probability $p_{i}$ that the fly count at trap $i$ exceeded the binary threshold, i.e. $\sum_{i}\left(y_{i}-p_{i}\right)^{2}$. The ROC curve is a plot of the sensitivity against false positive rate for a range of probability thresholds, assuming that the observed data are the true state of nature. From this curve it is possible to calculate the area under the curve (AUC) as a measure of how well the model is able to discriminate between the two categories. Both measures range between zero and one, with a Brier score of 0 and a ROC-AUC of 1 representing perfect discrimination.

Maps of estimated tsetse abundance were produced, with estimates being made on a $30 \mathrm{~m}$ by $30 \mathrm{~m}$ grid using 
functions within the R-INLA package (see Additional file 2: S2). Maps included the posterior mean fly abundance and the probability of exceeding relevant category thresholds. To disentangle the impact of the environmental covariates and the residual spatial correlation on the predictions a separate map of the latter was also produced.

\section{Results}

\section{Exploratory data analysis}

Of the 236 traps that were monitored during the baseline survey, 64 traps (27\%) did not catch any tsetse (Fig. 1). On reflecting on the initial study design, it was noted that the vast majority of traps which were placed in locations far from the river network rarely caught any flies (Fig. 2) in accordance with the expected distribution of riverine tsetse. Due to this observation, and the additional knowledge that current control interventions are focused on deploying "Tiny Targets" along river networks, the decision was made to focus only on modelling the variability in tsetse catches within close proximity to the rivers. Using an arbitrary distance threshold of $100 \mathrm{~m}$, this resulted in data from 198 traps being used to develop the abundance models. Of these 198 traps, 15\% traps (29/198) did not catch any flies, whereas in the remainder the fly abundance ranged from 0.3 to 114.5 flies per day with a median of 3.7.

Simple scatterplots were initially produced of the log-transformed average fly count (plus one, to avoid errors resulting from log-transforming zero) and the extracted environmental variables. Figure 3 presents a subset of these plots. There appeared to positive relationships between $\log$-transformed catch and distance to the river plus the length of river within a $350 \mathrm{~m}$ radius, however the relationship with other variables was less clear.

With regards to alternative sources of river data, after visually examining the relationship between flow accumulation and visible river networks in Google satellite imagery, proxy river shapefiles were derived using a flow accumulation threshold of 100 . There was a relatively weak significant relationship between the distances between the rivers and the traps obtained using the two river sources (Spearman's correlation, $r=0.35, P \leq 0.0001$ ), indicating that whilst the network obtained using the flow accumulation can give the approximate location of rivers in an area, this is not an overly precise way of identifying river paths at a small geographical scale (Fig. 4) due to the resolution of the digital elevation data being used $(30 \mathrm{~m})$.

\section{Zero-inflated negative binomial models}

Given the relatively large number of zeros in the dataset, plus evidence of additional overdispersion provided by several traps having very large catches ( $>100$ tsetse per day), a zero-inflated negative binomial (ZINB) geostatistical modelling approach was initially adopted. Following the systematic model fitting procedure, the variables included in the final ZINBGM-River model (Table 2) were distance to

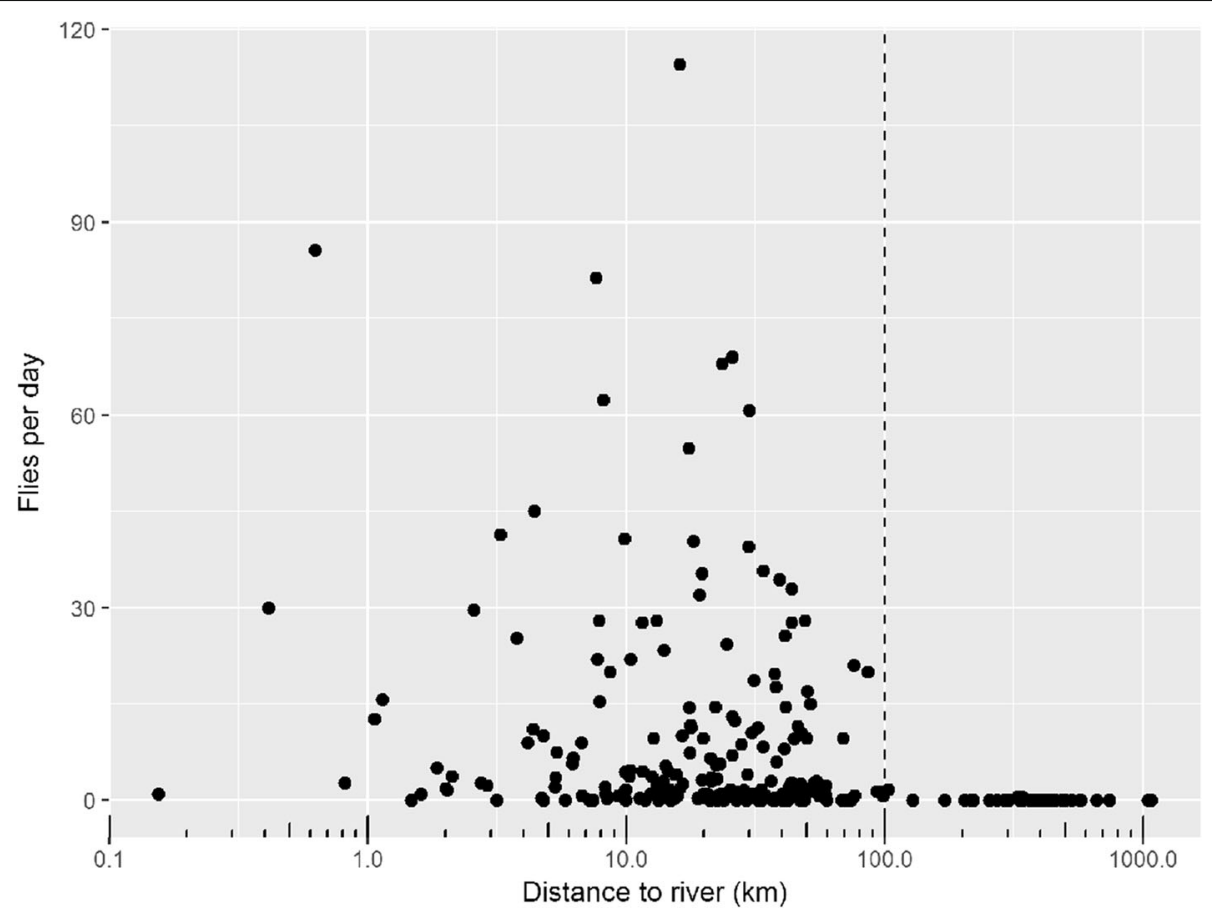

Fig. 2 A plot of average daily catch against Euclidean distance to the nearest river on the $\log _{10}$ scale. Traps within $100 \mathrm{~m}$ of the river (denoted by a dashed vertical line) were used to develop a geostatistical model of tsetse abundance 


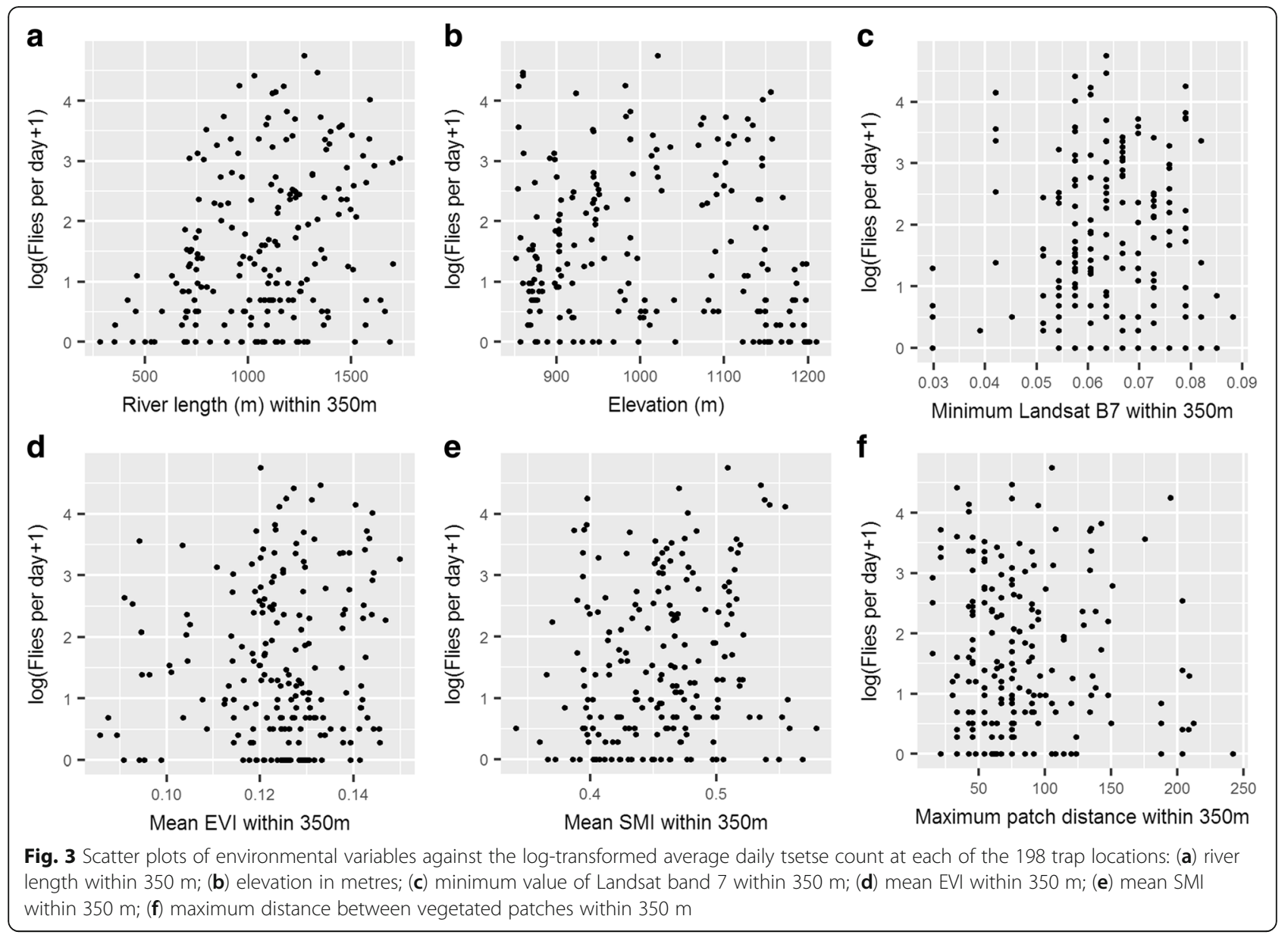

nearest river (in metres), excluding those classed as tributaries, elevation, log-transformed length of river within $350 \mathrm{~m}$, and the minimum value of Landsat band 7 within $350 \mathrm{~m}$, with river distance and elevation having a negative relationship with fly abundance, and river length and band 7 having a positive relationship. Similarly, the ZINBGM-Proxy model included a negative association with elevation and a positive association with a proxy measure of the proportion of the surrounding area covered by 'large' rivers, i.e. the square root of the proportion of surrounding cells (within $350 \mathrm{~m}$ ) with flow accumulation greater than 2000 and the minimum value of Landsat band 7 within $350 \mathrm{~m}$. In both instances the zero-inflated term was modelled using an intercept only had a lower WAIC (river model $=1454$, proxy model $=1464)$ than both the negative binomial with no zero-inflated component (river model $=1465$, proxy model $=1474$ ) and a zero-inflated Poisson model $($ river model $=2353$, proxy model $=2869$ ) . The WAIC for both zero-inflated models without a spatial component was also substantially larger (river model = 1562, proxy model $=1554$ ) indicating that after adjusting for the effects of the covariates there was still significant spatially structured variability in the data.

\section{Model evaluation}

Figure 5 presents a scatterplot of the observed average daily catch against the posterior mean average daily catch on the log scale for both models. Despite accounting for excess zeros in the model, the model still over-estimates the fly counts when the observed numbers are low but appears to under-predict when counts are high. The RMSE for the ZINBGM-River model was 15.2, in comparison to 15.4 for the ZINBGM-Proxy model. With regards to the ability of the model to categorise the fly counts correctly, Fig. 6 presents the violin plots of the fitted $p_{i c}$, i.e. the proportion of posterior samples for trap $i$ that were within the correct category $c, c=1,2,3$ where categories were based on the terciles of the trap data, i.e. low $=[0,1)$, medium $=[1,7.67)$, high $=[7.67,114]$. Whilst the fitted probability of counts correctly falling in the 'low' category is generally high (median $=0.70$ for both models), neither model is able to well distinguish between the medium and high categories. In reducing the data to two categories using an initial threshold of one fly per day, the ROC-AUC and Brier scores for the two models were similar (ROC_AUC: ZINB-River $=0.7869$, ZINB-Proxy $=0.7633 ;$ Brier: 
a

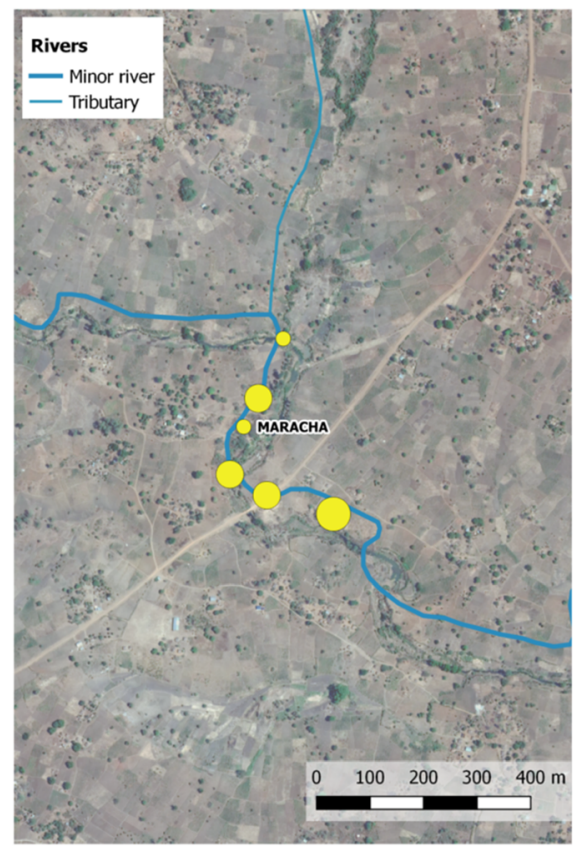

b

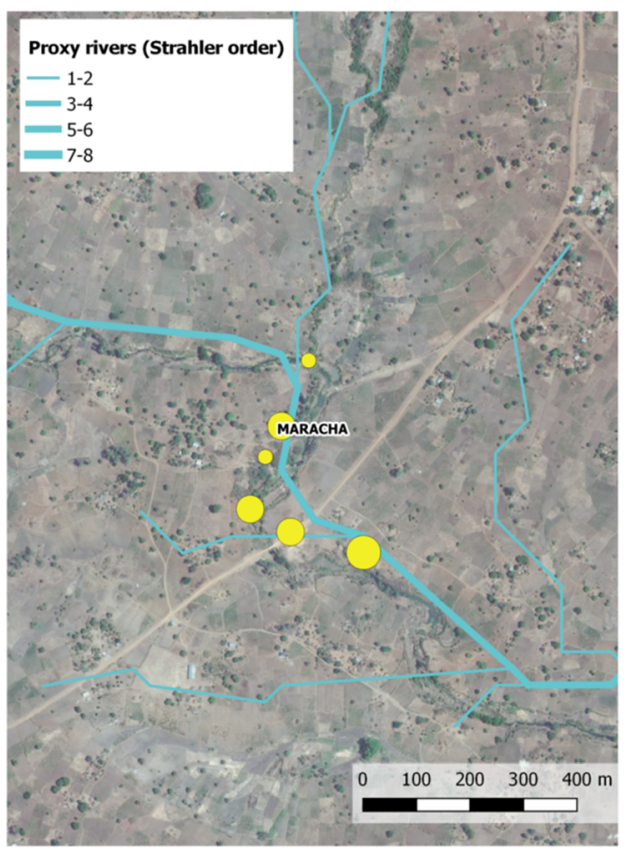

Fig. 4 Comparison of river network data obtained from the Government of Uganda (a) and derived from 30 m resolution digital elevation data using a flow accumulation threshold of 100 (b)

ZINB-River $=0.1949$, ZINB-Proxy $=0.2015$, with optimal thresholds for simultaneously maximising sensitivity and specificity of 0.54 and 0.60 for the two models, respectively. In considering a range of binary categories with thresholds ranging from the first quartile of the observed data ( 0.667 flies/day) to the third quartile ( 11.3 flies/day), the model performs best at distinguishing between areas with 'moderate' fly relative abundance. Figure 7 presents a plot of the ROC-AUC obtained using a range of categorisation thresholds for the ZINB-River model, depicting that the ROC-AUC exceeds 0.9 when the catch threshold exceeds 5 flies/day.

Figure 8 presents maps of the fitted spatial process obtained using the ZINBGM-River model, the posterior predictive mean number of flies per day, and the associated probability of exceeding five flies per day for areas within $100 \mathrm{~m}$ of the river network. After accounting for the variability in the selected environmental risk factors, it was observed that there were areas of higher than expected fly counts in the southern part of the study region, whereas lower than expected counts were observed in the north-east and the north-west (Fig. 8a). Figure 8b and $c$ indicated that large numbers of flies were expected, both in terms of the posterior mean of the predicted counts and in the predicted probability that the number of flies exceeded five per day, in the south east and south west of the study region.

\section{Discussion}

In this paper we consider estimating the relative abundance of tsetse using a zero-inflated negative binomial geostatistical modelling approach. Two sources of river

Table 2 Results of the fitted ZINBGM-River and ZINBGM-Proxy models

\begin{tabular}{|c|c|c|c|c|}
\hline Model & Covariates & Posterior mean & 95\% credible interval & WAIC \\
\hline \multirow[t]{4}{*}{ ZINBGM-River } & Distance to nearest river (excluding tributaries) & -0.0024 & $-0.0033,-0.0014$ & \multirow[t]{4}{*}{1454} \\
\hline & Elevation & -0.0060 & $-0.0143,0.0007$ & \\
\hline & Log (river length) within 350 m & 0.9808 & $0.2556,1.7092$ & \\
\hline & Min (Band 7) within $350 \mathrm{~m}$ & 15.54 & $-5.44,36.32$ & \\
\hline \multirow[t]{3}{*}{ ZINBGM-Proxy } & Elevation & -0.0060 & $-0.0142,0.0002$ & \multirow[t]{3}{*}{1464} \\
\hline & Sqrt (proportion with flow accumulation > 2000) within $350 \mathrm{~m}$ & 10.96 & $7.61,14.24$ & \\
\hline & Min (Band 7) within $350 \mathrm{~m}$ & 23.12 & $2.08,43.87$ & \\
\hline
\end{tabular}



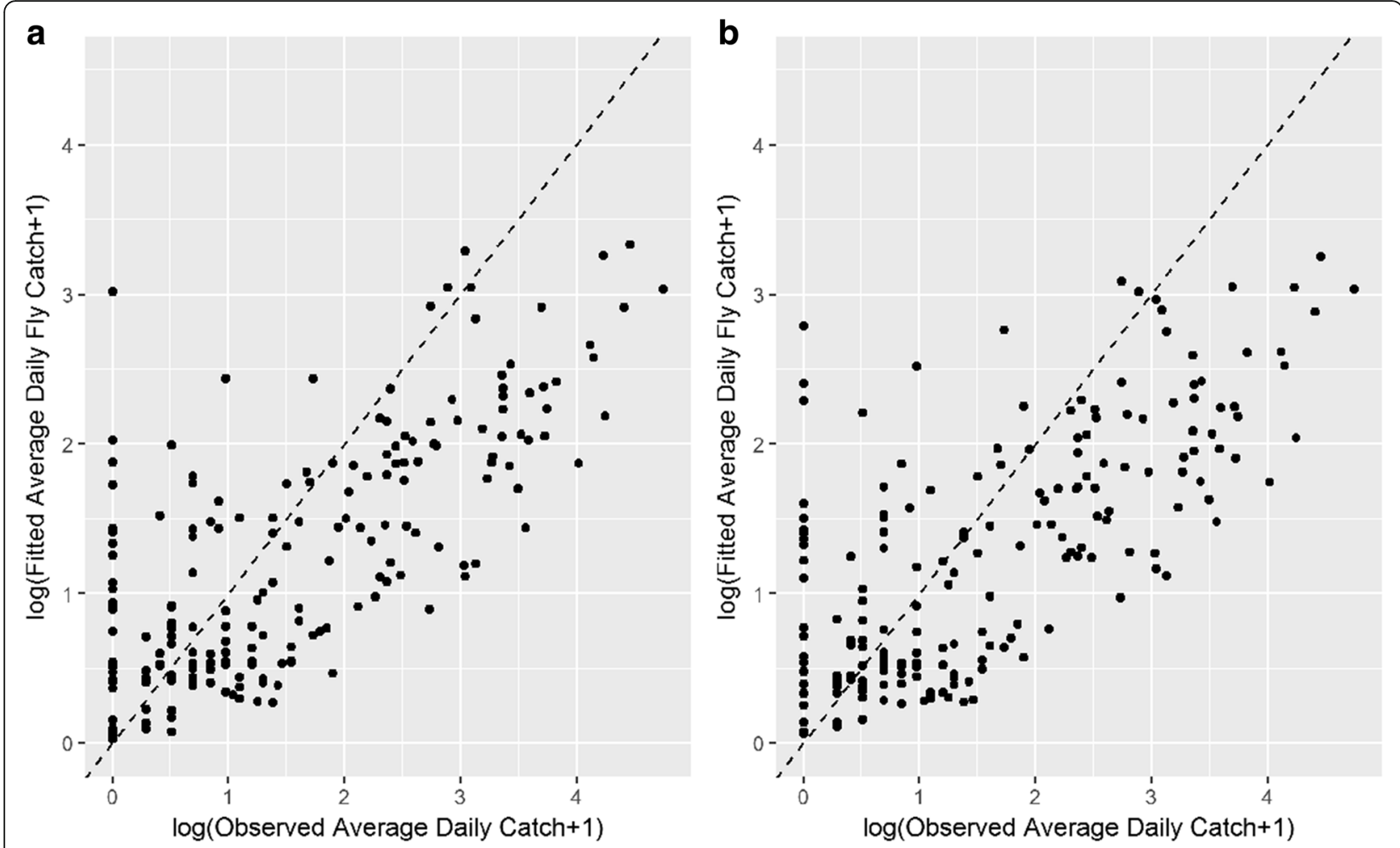

Fig. 5 Scatter plots of observed average daily tsetse count against mean fitted and the posterior mean daily tsetse count on the log scale obtained using data from the 198 traps for the ZINBGM-River model (a) and the ZINBGM-Proxy model (b)

network data were considered when fitting these models to account for scenarios where accurate locally-obtained river network information was available. Following a systematic model fitting approach, both types of model shared common environmental covariates including elevation, a measure of soil/vegetation moisture (Landsat 5

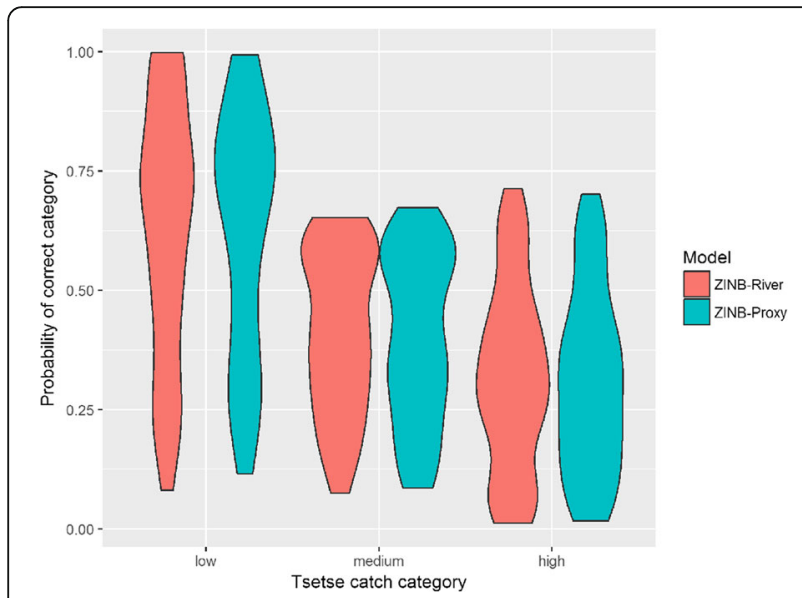

Fig. 6 Violin plots depicting the distribution of the posterior probability that the daily fly count was within the correct observed range of low, medium and high for the ZINBGM-River model (a) and the ZINBGM-Proxy model (b)
Band 7) and a measure of how much river water was in the surrounding area. As anticipated, given that the area was inhabited by riverine tsetse species, there was a negative relationship between the distance to larger rivers (i.e. excluding tributaries) and the relative abundance of tsetse using the more accurate locally-obtained river network data. It has long been recognised that G. f. fuscipes is found in more humid habitats in comparison to other subspecies (G. f. quanzensis, G. f. martini) [29] and laboratory studies have also shown that in comparison to six other species of tsetse, G. f. fuscipes was the least tolerant of arid environments [30].

Proxy river data derived using digital elevation data (30 $\mathrm{m}$ resolution) could assist in identify the general location of rivers, including the 'amount' of water within an area, but it could not be used to estimate the precise distance between traps and the river at a small spatial scale $(<100 \mathrm{~m})$. This result highlights the need to obtain as accurate water network data as possible when developing local-scale models for riverine tsetse. Other remotely sensed-based methods in addition to those employed in this paper are available to identify river networks, such as those based on land cover/land use classification [31, 32]. Given that the rivers in this area were generally quite narrow we however found that the spatial resolution of publicly available contemporary remote 


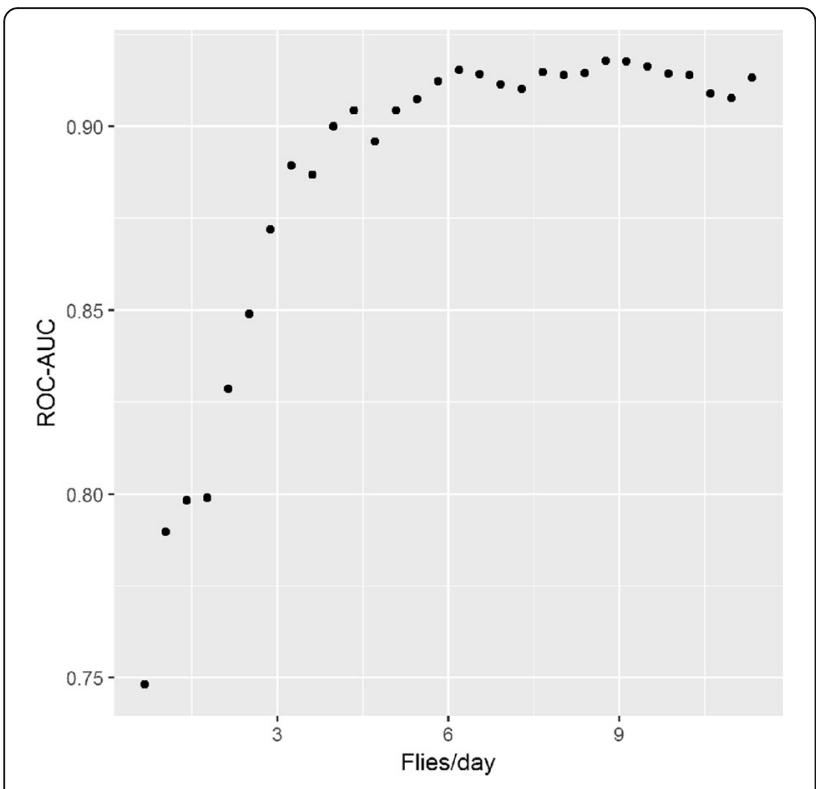

Fig. 7 Performance of the ZINBGM-River model with respect to categorising the traps into two categories-based thresholds ranging from 0.667 flies/day to 11.667 flies per day. Performance is measured using the ROC-AUC measure

sensing data such as Landsat was inadequate for this task. As more remote sensing resources become available, for example Sentinel-2 launched in June 2015 collects data with a spatial resolution of $10 \mathrm{~m}$, more accurate river network information will be increasingly accessible.

Landsat 5 data from a single time point in December 2009 , i.e. one year prior to the collection of the tsetse count data were used to conduct this analysis, as contemporary data were not available due to cloud cover. Whilst this is a limitation in this analysis, the authors note that in areas where no "Tiny Targets" were deployed there was little observed seasonal or inter-annual variability in tsetse catches [4]. As such, it was feasible to use relatively recent satellite imagery to explore the relationship between the environment and tsetse catches.

The analysis conducted in this paper focused on explaining the variability in tsetse catches within close proximity to rivers (as identified using Government of Uganda maps). This decision was driven by the observation that flies were rarely found in sampling sites away from the river network during the sampling period. Whilst this was an appropriate decision to make given the available data, it is important to acknowledge the importance of verifying the spatial extent of riverine tsetse habitat when surveying new areas, as tsetse may be more dispersed elsewhere.

Previous research into mapping tsetse has focused on mapping the probability of tsetse presence either using presence/absence data and approaches such as logistic regression and discriminant analysis, or presence only data using approaches such as MaxEnt [10, 33, 34]. Whilst this approach is useful in identifying general areas where tsetse control is appropriate, in settings such as northern Uganda where tsetse densities are generally high, there is a greater interest in gaining an understanding of fly density variability for the purposes of guiding and prioritising control efforts. To the authors knowledge, this is the first paper to develop maps of estimated abundance of T. b. gambiense. Whilst the efficiency of the pyramidal traps used in this study are affected by a number of factors in addition to the surrounding fly density, the presented zero-inflated negative binomial models were still able to detect trends in the number of flies caught and the surrounding environment, and enabled areas with high versus low fly numbers to be differentiated. Such information could assist in the planning and implementation of tsetse control
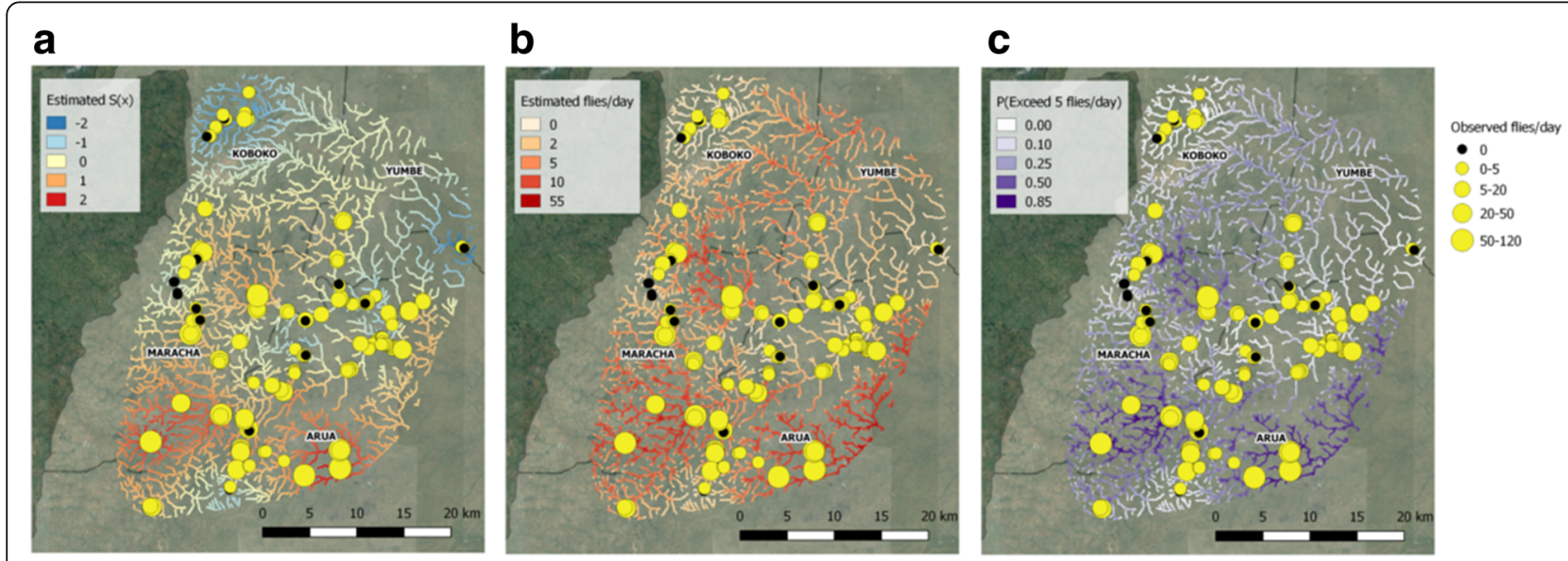

Fig. 8 Maps of the spatial term obtained from fitting the ZINBGM-River model (a), the estimated catch per day (b) and probability of exceeding the threshold of five flies/day (c) 
operations in several respects. First, it provides a fine-scale map of the likely distribution and abundance of tsetse which can guide where targets should be deployed and the required frequency of the deployment [35]. Secondly, the identification of areas where tsetse are predicted to be abundant and hence serve as sites for entomological monitoring of control operations. Thirdly, improved knowledge of the local distribution and abundance will also assist in the identification of sites where disease risk is greater. These 'hotspots' may warrant increased monitoring of the human and vector populations and/or enhanced levels of vector control. Finally, by quantifying relationships between environmental variables and tsetse we have the basis of a method to predict the likely impact of changes in land-use on tsetse and tsetse-borne diseases.

The data used to develop these models were collected over a short time period during the dry season, over a relatively small area with limited environmental variability. With the aim of expanding the control of tsetse over larger geographical areas, the focus is now on developing these models further to ensure that they remain valid for larger geographical areas where tsetse control has not yet been implemented in northern Uganda, South Sudan and eastern parts of the Democratic Republic of Congo where G. f. fuscipes spreads Gambian sleeping sickness. A similar approach has also been adopted to predict the distribution and abundance of savanna species of tsetse in Tanzania [36].

\section{Conclusions}

There is a growing body of evidence that vector control can make a valuable contribution to the control Gambian sleeping sickness in addition to active and passive screening and treatment of the human population [37]. Vector control relies on identifying areas where tsetse are present so that the vector control can be applied cost-effectively. Analysis of the relationship between remotely sensed environmental variables and the numbers of riverine tsetse, i.e. G. f. fuscipes caught from traps, showed that we were able to predict daily average fly catches, and differentiate between areas of high and low fly counts. These models can now be used to assist in the design, implementation and monitoring of tsetse control operations to eliminate Gambian HAT in northern Uganda and further can be used as a framework by which to undertake similar studies in other areas where G. f. fuscipes spreads Gambian sleeping sickness.

\section{Additional files}

Additional file 1: Tsetse data and their associated environmental covariates at each of the 236 baseline trapping sites. (CSV $48 \mathrm{~kb}$ )
Additional file 2: $\mathrm{R}$ code demonstrating the use of INLA to fit zeroinflated negative binomial geostatistical models to the tsetse count data. (R $4 \mathrm{~kb}$ )

\begin{abstract}
Abbreviations
AUC: area under the curve; HAT: Human African trypanosomiasis; INLA: Integrated Nested Laplace Approximation; RMSE: root mean squared error; ROC: receiveroperating curve
\end{abstract}

\section{Acknowledgements \\ We would like to thank Mr Clements Mangwiro for his field assistance.}

\section{Funding}

This work is supported by the Medical Research Council (grant number MR/ M014975/1) and the Bill and Melinda Gates Foundation [grant number 1017770, 1104516]. The funders did not have any role in the study.

Availability of data and materials

All data generated or analysed during this study are included in this published article and its additional files.

\section{Authors' contributions}

SJT, IT and JE made substantial contributions to the collection of the tsetse count data. MCS and HB extracted and derived the environmental data. MCS and SJT were major contributors in the conception and design of the study. MCS analysed and interpreted the data. MCS and SJT drafted the manuscript. All authors read and approved the final manuscript.

Ethics approval and consent to participate

Not applicable.

\section{Competing interests}

The authors declare that they have no competing interests.

\section{Publisher's Note}

Springer Nature remains neutral with regard to jurisdictional claims in published maps and institutional affiliations.

\section{Author details}

${ }^{1}$ Lancaster Medical School, Lancaster University, Lancaster, UK. ${ }^{2}$ Vector Biology Department, Liverpool School of Tropical Medicine, Liverpool, UK. ${ }^{3}$ Parasitology Department, Liverpool School of Tropical Medicine, Liverpool, UK.

Received: 24 January 2018 Accepted: 28 May 2018

Published online: 08 June 2018

\section{References}

1. Franco JR, Simarro PP, Diarra A, Jannin JG. Epidemiology of human African trypanosomiasis. Clin Epidemiol. 2014;6:257-75.

2. Cecchi G, Paone M, Argilés Herrero R, Vreysen M, Mattioli R, Kristjanson P, et al. Developing a continental atlas of the distribution and trypanosomal infection of tsetse flies (Glossina species). Parasit Vectors. 2015;8:284

3. World Health Organization. Global Health Observatory Data Repository. 2016. http://apps.who.int/gho/data/node.main.A1636?lang=en. Accessed 22 May 2018.

4. Tirados I, Esterhuizen J, Kovacic V, Mangwiro TNC, Vale GA, Hastings I, et al. Tsetse control and Gambian sleeping sickness; Implications for control strategy. PLoS Negl Trop Dis. 2015;9:e0003822.

5. Lehane M, Alfaroukh I, Bucheton B, Camara M, Harris A, Kaba D, et al. Tsetse control and the elimination of Gambian sleeping sickness. PLoS Negl Trop Dis. 2016:10:e0004437.

6. Shaw APM, Tirados I, Mangwiro CTN, Esterhuizen J, Lehane MJ, Torr SJ, et al. Costs of using "tiny targets" to control Glossina fuscipes fuscipes, a vector of gambiense sleeping sickness in Arua District of Uganda. PLoS Negl Trop Dis. 2015:9:e0003624.

7. Simarro PP, Cecchi G, Franco JR, Paone M, Diarra A, Priotto G, et al. Monitoring the progress towards the elimination of Gambiense Human African trypanosomiasis. PLoS Negl Trop Dis. 2015;9:e0003785. 
8. Simarro P, Franco J, Diarra A, Ruiz Postigo J, Jannin J. Diversity of human African trypanosomiasis epidemiological settings requires fine-tuning control strategies to facilitate disease elimination. Res Rep Trop Med. 2013;4:1-6.

9. Giddings L, Naumann A. Technical Memorandum JSC - 11652 (2nd edn), Remote sensing for control of tsetse flies, NASA. 1976.

10. Dicko AH, Lancelot R, Seck MT, Guerrini L, Sall B, Lo M, et al. Using species distribution models to optimize vector control in the framework of the tsetse eradication campaign in Senegal. Proc Natl Acad Sci USA. 2014;111: 10149-54.

11. Matawa F, Murwira KS, Shereni W. Modelling the distribution of suitable Glossina spp. habitat in the north western parts of Zimbabwe using remote sensing and climate data. Geoinformatics Geostatistics An Overv. 2013;S1: S1-S016.

12. Rogers DJ. Satellites, space, time and the African trypanosomiasis. Adv Parasitol. 2000:47:129-71.

13. Kovalskyy V, Roy DP. The global availability of Landsat 5 TM and Landsat 7 ETM+ land surface observations and implications for global 30 m Landsat data product generation. Remote Sens Environ. 2013;130:280-93.

14. Dowman I, Reuter HI. Global geospatial data from Earth observation: status and issues. Int J Digit Earth. 2016;10:328-41.

15. Gouteux JP, Lancien J. The pyramidal trap for collecting and controlling tsetse flies (Diptera: Glossinidae). Comparative trials and description of new collecting technics. Trop Med Parasitol. 1986;37:61-6.

16. Kitron U, Otieno L, Hungerford L, Odulaja A, Brigham W, Okello O, et al. Spatial analysis of the distribution of tsetse flies in the Lambwe Valley, Kenya, Using Landsat TM satellite imagery and GIS. J Anim Ecol. 1996:65:371-80

17. Rogers D. Study of a natural population of Glossina fuscipes fuscipes Newstead and a model of fly movement. J Anim Ecol. 1977:46:309.

18. Guerrini L, Bord JP, Ducheyne E, Bouyer J, Aubreville A, Bouyer J, et al. Fragmentation analysis for prediction of suitable habitat for vectors: example of riverine tsetse flies in Burkina Faso. J Med Entomol. 2008;45:1180-6.

19. Ducheyne E, Mweempwa C, De Pus C, Vernieuwe H, De Deken R, HendrickX $\mathrm{G}$, et al. The impact of habitat fragmentation on tsetse abundance on the plateau of eastern Zambia. Prev Vet Med. 2009;91:11-8.

20. Mweempwa C, Marcotty T, De Pus C, Penzhorn BL, Dicko AH, Bouyer J, et al. Impact of habitat fragmentation on tsetse populations and trypanosomosis risk in Eastern Zambia. Parasit Vectors. 2015:8:406.

21. Lindgren F, Rue H. Bayesian spatial modelling with R - INLA. J Stat Softw. 2015;63:1-25.

22. Rue H, Martino S, Chopin N. Approximate Bayesian inference for latent Gaussian models by using integrated nested Laplace approximations. J R Stat Soc Ser B (Statistical Methodol). 2009;71:319-92.

23. Bivand RS, Gómez-Rubio V, Rue H. Spatial Data Analysis with R - INLA with Some Extensions. J Stat Softw. 2015;63:1-31

24. Lindgren F, Rue H, Lindström J. An explicit link between Gaussian fields and Gaussian Markov random fields: the stochastic partial differential equation approach. J R Stat Soc Ser B (Statistical Methodol). 2011;73:423-98.

25. R-INLA. The R-INLA project: Likelihoods [Internet]. 2016. Available from: http://www.r-inla.org/models/likelihoods. Accessed 22 May 2018.

26. Gelman A, Carlin JB, Stern HS, Dunson DB, Vehtari A, Rubin DB. Bayesian data analysis. 3rd ed. Florida. USA: CRC Press; 2013.

27. Brier GW. Verification of forecasts expressed in terms of probability. Mon Weather Rev. 1950;78:1-3.

28. Hanley JA, Receiver operating characteristic (ROC) curves. Wiley StatsRef Stat Ref Online. UK: John Wiley \& Sons, Ltd; 2014

29. Machado A de B. Révision systématique des glossines du groupe palpalis Diptera. Publicacoes Cult da Cia Diam. Angola. 1954;22:1-189.

30. Bursell E. The water balance of tsetse pupae. Philos Trans R Soc Lond B Biol Sci. 1958:241:179-210.

31. Yang K, Li M, Liu Y, Cheng L, Duan Y, Zhou M. River delineation from remotely sensed imagery using a multi-scale classification approach. IEEE J Sel Top Appl Earth Obs Remote Sens. 2014;7:4726-37.

32. Jiang $H$, Feng $M$, Zhu $Y$, Lu N, Huang J, Xiao T. An automated method for extracting rivers and lakes from Landsat imagery. Remote Sens. 2014;6: 5067-89.

33. Robinson T, Rogers D, Williams B. Mapping tsetse habitat suitability in the common fly belt of southern Africa using multivariate analysis of climate and remotely sensed vegetation data. Med Vet Entomol. 1997;11:235-45.
34. Rogers DJ, Williams BG. Monitoring trypanosomiasis in space and time. Parasitology. 1993;106:S77-92.

35. Vale GA, Hargrove J, Lehane MJ, Solano P, Torr SJ. Optimal strategies for controlling riverine tsetse flies using targets: a modelling study. PLoS Negl Trop. 2015;9:e0003615

36. Lord J, Torr S, Augty H, Brock P, Byamunga M, Hargrove J, et al. Geostatistical models using remotely-sensed data predict savanna tsetse decline across the interface between protected and unprotected areas in Serengeti, Tanzania. J Appl Ecol. 2018;00218901. https://besjournals.onlinelibrary.wiley.com/doi/full/ 10.1111/1365-2664.13091

37. Rock KS, Torr SJ, Lumbala C, Keeling MJ. Quantitative evaluation of the strategy to eliminate human African trypanosomiasis in the Democratic Republic of Congo. Parasit Vectors. 2015;8:532.

38. Wang L, Qu JJ. Satellite remote sensing applications for surface soil moisture monitoring: A review. Front Earth Sci China. 2009:3:237-47.

39. Ndossi MI, Avdan U. Application of open source coding technologies in the production of land surface temperature (LST) maps from Landsat: a PyQGIS plugin. Remote Sens. 2016;8:413.

\section{Ready to submit your research? Choose BMC and benefit from:}

- fast, convenient online submission

- thorough peer review by experienced researchers in your field

- rapid publication on acceptance

- support for research data, including large and complex data types

- gold Open Access which fosters wider collaboration and increased citations

- maximum visibility for your research: over $100 \mathrm{M}$ website views per year

At BMC, research is always in progress.

Learn more biomedcentral.com/submissions 